\title{
How are tension-free vaginal tapes (TVT) used in the United Kingdom?
}

Published online: 30 April 2004

(C) Springer-Verlag Berlin / Heidelberg 2004

\begin{abstract}
Objective: The purpose was to ascertain how tension-free vaginal tape (TVT) slings are used in the United Kingdom. Methods: A postal questionnaire was sent to all 446 gynaecologists and urologists thought to be using TVT sling surgery in the UK. Results: There was wide variation in technique amongst the 236 respondents. These varied with respect to the type of anaesthetic and place of surgery, use of cystoscopy and cough test and postoperative management. Conclusion: Although there is a wide variation in technique, it does not appear to affect outcome since results are broadly comparable from different units.
\end{abstract}

Keywords TVT $\cdot$ UK $\cdot$ Surgical technique $\cdot$ Variation

\section{Introduction}

The tension-free vaginal tape (TVT-Gynecare) procedure was first described by Ulmsten in 1996 [1]. Since then, a huge number of papers have been published that testify to the effectiveness of the procedure $[2,3]$. The TVT procedure has revolutionised the surgical management of urodynamic stress incontinence [4] and has now been recommended as the technique of choice by the National Institute for Clinical Excellence (NICE) [5]. Many thousands of TVTs have been carried out, but it is uncertain how many were performed as Ulmsten originally described. There is a natural tendency for surgical techniques to evolve with time yet still carry the original name of the operative procedure. This study was therefore carried out to investigate the variation in TVT technique in the United Kingdom.

J. W. Barrington $(\bullet) \cdot$ M. Abdel-fattah $\cdot$ F. Bano Department of Obstetrics and Gynaecology,

Torbay Hospital, Torquay, Devon, TQ2 7AA, UK e-mail: julian.barrington@nhs.net

\section{Materials and methods}

A questionnaire was sent to all surgeons listed on the Gynecare database in the UK who were known to or thought to be carrying out TVT $(n=446)$. The surgeons were asked to identify themselves as gynaecologists or urologists and the institution in which they worked. They were asked approximately how many TVT procedures they carried out annually, whether they carried out preoperative urodynamics and whether they carried out TVT in the outpatient department, day surgery unit or as inpatients. The type of anaesthetic was requested and whether the surgeons used the concept of aqua dissection. The respondents were asked if they used a catheter introducer and, if so, what size catheter they used. They were asked if a cystoscopy was routinely carried out and whether this was carried out after each or both passes of the needle. The surgeons were asked whether they routinely used a cough test and, if so, at what bladder volume. They were asked whether the urethra was checked after the removal of the plastic sheath to ensure the sling was not too tight and, if so, what size dilator was used. They were asked whether a catheter was inserted at the completion of the procedure and, if so, whether a suprapubic or urethral catheter was used. They were asked what postoperative volume was deemed acceptable for discharge, whether the patients returned for followup and, if so, how long postoperatively.

\section{Results}

Two hundred and fifty replies were received, including 14 from surgeons who did not perform the procedure. This left 236 (53\%) replies from 200 gynaecologists and 36 urologists for analysis: 184 replies were from district general hospitals, 43 from teaching hospitals and 9 from regional referral centres, which represents approximately 8,386 annual TVT procedures (range 3-200, mean 36, median 25) and is therefore representative of practice in the UK. Preoperative urodynamics were carried out in 222 units $(94 \%)$. The majority of respondents carry out TVT for inpatients alone $(n=173)$ compared with day surgery units alone $(n=22)$. Forty surgeons carried out TVT in both day surgery and on inpatients, with only one surgeon carrying out TVT in the outpatient department. The type of anaesthetic varied widely from local anaesthetic alone $(n=15)$, local anaesthetic plus sedation $(n=32)$, general anaesthetic alone $(n=32)$, regional an- 
aesthetic alone $(n=63)$ and a mixture of anaesthetics $(n=94)$. Opinion was divided concerning aqua dissection, with 125 respondents using this technique compared with 111 against it. The amount of local anaesthetic used ranged from 20-200 mls (mean $92 \mathrm{mls}$, median $90 \mathrm{mls}$ ). Almost all surgeons use a catheter introducer $(n=211$, $89 \%$ ), with an average size of $18 \mathrm{~g}$. All surgeons (100\%) carry out an intraoperative cystoscopy, with 108 doing a cystoscopy after each needle pass and 128 after both needles have been passed. Two hundred surgeons use a cough test compared to 36 who are against it: the majority $(n=144)$ simply filled the bladder to an approximate volume (range 150-1,000 mls, mean $368 \mathrm{mls}$, median $350 \mathrm{mls}$ ). Three surgeons filled the bladder to the leak point pressure on urodynamics, eight filled to bladder capacity on urodynamics and ten used other measurements prior to a cough test. The majority $(n=125)$ do not routinely check the urethra after removal of the covering plastic sheaths. Those that do $(n=101)$ use an average of an 8-hagar gauge or 18 French gauge dilator. The use of a catheter at the completion of the operation was equally divided: 115 of respondents who do use a catheter preferred urethral $(\mathrm{n}=109)$ instead of suprapubic catheters $(n=6)$. The majority of surgeons $(n=142)$ use a post-void residual bladder volume of $<100 \mathrm{mls}$ as acceptable for discharge: 62 use a residual of between 100 $200 \mathrm{mls}, 10$ used a voided volume equal or greater than twice the voided volume, and 22 use other criteria. Two hundred twenty-nine of the surgeons follow up patients at between 1-52 weeks (mean 8 weeks, median 10 weeks).

\section{Discussion}

This study has shown that there are considerable variations in the way TVT is used in the UK and also between the opinions of gynaecologists and urologists. Despite this, the essential question is whether variation from the original description by Ulmsten affects the outcome. The vast amount of published data fail to support this, and therefore outside the context of scientific trials there should be no contraindication to variation in technique.

\section{References}

1. Ulmsten U, Henriksson L, Johnson P, Varhos G (1996) An ambulatory surgical procedure under local anesthesia for treatment of female urinary incontinence. Int Urogynecol J Pelvic Floor Dysfunction 7:81-86

2. Ulmsten U, Johnson P, Rezapour M (1999) A 3-year follow-up of tension-free vaginal tape for surgical treatment of female stress urinary incontinence. Brit J Obstet Gynaecol 106:345350

3. Nilsson CG (1998) The TVT procedure for the treatment of female stress urinary incontinence. Acta Obstet Gynaecol 168:34-37

4. Ward KL, Hilton P (2002) Prospective multicentre randomised trial of tension-free vaginal tape and colposuspension as primary treatment for stress incontinence. Brit Med J 325:67

5. National Institute for Clinical Excellence (2003) Guidance on the use of tension-free vaginal tape (Gynecare TVT) for stress incontinence. Technology Appraisal Guidance no. 5 